\title{
Sink-source Transition in Peach Leaves during Shoot Development
}

\author{
Susanna Marchi ${ }^{1}$ and Luca Sebastiani \\ BioLabs, Scuola Superiore "Sant'Anna" di Studi Universitari e di Perfezionamento, Piazza Martiri \\ della Libertà 33, I-56127 Pisa, Italy \\ Riccardo Gucci \\ Dipartimento di Coltivazione e Difesa delle Specie Legnose, Università di Pisa, Via del Borghetto 80, \\ I-56124 Pisa, Italy \\ Roberto Tognetti \\ Dipartimento di Scienze Animali, Vegetali e dell'Ambiente, Università degli Studi del Molise, Via De \\ Sanctis, I-86100 Campobasso, Italy
}

\begin{abstract}
Additional INDEX words. $\mathrm{CO}_{2}$ assimilation, carbon balance, leaf expansion, Prunus persica, sigmoid growth
Abstract. Net photosynthesis, dark respiration, chlorophyll and carbohydrate content, and leaf and shoot growth of deciduous peach [Prunus persica $\left(\mathrm{L}_{\text {. }}\right)$ Batsch] saplings, grown in greenhouse conditions, were measured to assess changes in carbon balance during leaf development. The 6th, 12th, and 16th leaf node were measured from the first flush at the base through expansion to maturity (the first node being the oldest). Shoot and leaves expanded following a sigmoid pattern in all nodes. The shape of the logistic curve did not vary between the 6th and the 16th leaf node, while the 12th leaf node showed a steeper response, suggesting that the latter reached $50 \%$ expansion relatively earlier. Photosynthesis varied with leaf development as young leaves had low $\mathrm{CO}_{2}$ assimilation rates that were reflected in their chlorophyll concentration. Net daily $\mathrm{CO}_{2}$ assimilation was negative in young expanding leaves. The sink-source transition, defined to be the time when the increase in daily carbohydrate exchange rate exceeded the daily increase in leaf carbohydrate content, occurred before full leaf expansion. The transition from import to export was attained 11-12 days after budbreak (corresponding to $41 \%$ to $45 \%$ of full leaf expansion) for the 6th leaf, about $7-9$ days after (38\% to $52 \%$ of full expansion) for the 12th leaf and after 9-10 days (32\% to $38 \%$ of full expansion) for the 16th leaf. Below $30 \%$ to $50 \%$ of full expansion leaves might not respond to assimilate requirements from sinks, being sinks themselves.
\end{abstract}

Leaves are the main source of $\mathrm{CO}_{2}$ assimilation in plants. Photosynthetic rates are generally low in young expanding leaves and increase up to or slightly after full leaf area expansion (Turgeon and Webb, 1975). As carbohydrates accumulate, import stops and the export of soluble sugars begins. In early phases of leaf growth, a leaf is a net carbon importer (sink), its growth depending mainly on a supply of imported substances. Afterwards a leaf becomes a net carbon exporter (source), its growth depending primarily on its photosynthates. This sink stage of leaf development may take several days or weeks. Leaves of dicotyledonous plants change from sink to source when their area reaches $30 \%$ to $60 \%$ of the final area (Turgeon, 1989).

The position and distribution of leaves along the shoot influences sink strength. The direction of translocation of assimilates varies with the developmental stage of single leaves. Fully developed apical leaves export carbohydrates toward younger leaves, basal leaves send carbohydrates to the shoot and roots, intermediate leaves in both directions (Dickson and Isebrand, 1991). Because large amounts of carbohydrates are used in respiration by sinks, absolute growth rate or rate of accumulation of dry matter does not accurately measure the capacity of a sink to receive assimilates. A more appropriate index of actual sink strength is the sum of net carbon gain minus respiratory carbon loss. During early stages of leaf growth, syntheses of chlorophyll, proteins and structural compounds are high, resulting in high

Received for publication 14 Mar. 2005. Accepted for publication 16 May 2005. Corresponding author: phone +39-050-883070; fax +39-050-883495; e-mail marchi@sssup.it catabolic rates to support the energy need. As the photosynthetic system matures, the requirement for respiratory energy rapidly decreases (Kozlowski, 1992).

In temperate fruit trees new leaves expand during flowering and compete for resources with developing fruits, although eventually they are net contributors to the carbon economy of the tree (Kriedemann, 1968). In spring season, deciduous species make new leaves at a low cost of carbon per unit leaf area, but at a high cost in terms of carbohydrate reserves (Dickson, 1989). Kennedy and Johnson (1981) studied gas exchange in expanding leaves of apples (Malus $\times$ domestica Borkh.) and found that net $\mathrm{CO}_{2}$ assimilation increased from 5 to $25 \mu \mathrm{mol} \cdot \mathrm{m}^{-2} \cdot \mathrm{s}^{-1}$ as the leaves expanded from 5 to $70 \%$ of final size. This increase in net $\mathrm{CO}_{2}$ assimilation was accompanied by increases in stomatal conductance. Escobar-Gutiérrez and Gaudillére (1996), comparing source and sink leaves, observed that the synthesis of soluble carbohydrates, in peach [Prunus persica (L.) Batsch.] was confined to source leaves, while the utilization of carbohydrates was limited to sink leaves. Sink-source relationships and the regulation of carbon allocation determine crop yield in fruit trees. The dynamic of the leaf development in source (assimilate availability) and sink (ability to utilize assimilates) limitations to crop yield in peach needs to be clarified in carbon balance models. Such models can incorporate and integrate growth functions, developmental patterns and environmental conditions, following the concept that plants grow as collections of semiautonomous but interacting organs (DeJong, 1999; Grossman and DeJong, 1994).

There is a strong interdependency among leaf life-span, net assimilation, leaf nitrogen concentration, leaf mass to area ratio, and habitat resource availability that may result from the neces- 
sity for allocation trade-offs either enhancing productivity or persistence of leaves (Reich et al., 1992). Indeed, differences among species in leaf life-span and associated traits reflect their differentiations in growth rate and in specific habitat. Changes in assimilation responses to the environment due to adjustments in carbon balance may result from altered ontogeny or morphological variations associated with increasing leaf age.

The transition from import to export is a function of the development of the photosynthetic systems during leaf ontogeny with the achievement of a net positive carbon balance. In this study, we report on changes in growth, chlorophyll concentration and net $\mathrm{CO}_{2}$ assimilation during shoot development of peach plants grown in greenhouse, with the aim to implement a framework for understanding how peach trees function in the orchard environment. In the course of their leaf ontogeny, we followed variations in carbohydrate contents for estimating sink-source transition of the 6th, 12th, and 16th node. We used the first flush to test the relationship between development and physiology because growth is confined to a single axis with leaves, stem and roots, without the complications of flowers and fruits. We hypothesized that young leaves would have assimilation potential lower than mature leaves and that differences in the sink-source transition between layers would be reflected in leaf development.

\section{Materials and Methods}

Plant material and growth Conditions. Seventy 1-year-old saplings from 'BigTop' peach on 'GF677' rootstock (P. persica $\mathrm{X}$ $P$. amygdalus Batsch.) were grown in 5-L plastic pots. All plants were trained to a single shoot. Pots containing a 1 loam : 1perlite : 1 field soil mix (by volume) were watered regularly to field capacity. Plants were grown in a naturally illuminated greenhouse (Pisa, lat. $43^{\circ} 43^{\prime} \mathrm{N}$, long. $10^{\circ} 23^{\prime} \mathrm{E}$ ), covered with a nursery net to reduce incoming radiation. Environmental conditions were continuously monitored during the measurement period; maximum photosynthetic photon flux density was $600 \mu \mathrm{mol} \cdot \mathrm{m}^{-2} \cdot \mathrm{s}^{-1}$, nighttime and daytime temperature ranging $9-13^{\circ} \mathrm{C}$ and $20-26$ ${ }^{\circ} \mathrm{C}$, respectively. At the beginning of leaf area expansion (early March) plants were fertilized with $100 \mathrm{~mL}$ half-strength Hoagland solution; the treatment was repeated approximately every $20 \mathrm{~d}$ throughout the experiment. Pests were controlled and plants manually weeded. Plants were subdivided in 10 control and 60 experimental individuals, and the latter sorted in 20 plants for each node in order to cover the whole leaf expansion interval.

Growth analysis. Shoot length, number of leaves (node from the base) and area of all leaves were monitored on 10 control plants approximately every $5 \mathrm{~d}$, throughout the experimental period. The dimension of each leaf (lamina length, $L$, and lamina width, $l)$ was measured and converted to leaf area $(L A)$, using $L A=0.6487(L \times l)+0.4442, n=72, r^{2}=0.99$. This curve $(P<$ $0.0001)$ was established from preliminary destructive leaf sampling and measurement of leaf area with a planimeter (LI-3000; LI-COR, Lincoln, Nebr.).

The growth of shoots and leaves was expressed as a function of time by a logistic equation fitted for each plant:

$$
y=\frac{a}{1+\left(\frac{x}{c}\right)^{b}}
$$

where $x$ indicates the time in days from budbreak, and $a, b$, and $c$ are constants defining the shape of the response. The asymptote $a$ was fixed equal to the maximum shoot length or leaf area (cm and $\mathrm{cm}^{2}$, respectively), reached when the apical bud was formed; $b$ is the width of the gradual transition from low to high values (dimensionless units, curvature of the growth pattern) and $c$ represents the value (days, curve displacement along the $x$-axis) in which the function is halfway of its width (inflection point at which the growth rate reaches its maximum value). A sigmoid equation cannot explicitly predict an actual "value" equal to parameter $a$ because it has the line "value" equal to $a$ as its upper asymptote when time tends to infinity. As a consequence, the length of the growth period is infinite in sigmoid-like equations, contravening the pattern of determinate growth. To achieve a set final value at the end of a precisely defined growth period, a segmented terminate function is needed (see Yin et al., 2003). Therefore, the maximum leaf area for each node or shoot length measured on the same plant material and growth conditions for two consecutive years, was used as a determinate growth limit. This model was fitted to the data by an iterative process of the Marquardt-Levenberg algorithm (SigmaPlot; Jandel Scientific, San Rafael, Calif.). This equation was used for estimating leaf age based on leaf area (for extrapolating back leaf age of experimental plants, through their area).

Variations in growth rate of leaves over the course of their individual surface expansion and of shoots during their individual length development were expressed logarithmically:

$R_{\mathrm{G}}$ (relative change in leaf area or shoot length) $=\left(\operatorname{lng}_{2}-\operatorname{lng}_{1}\right)$ $/\left(t_{2}-t_{1}\right)$

in which $\mathrm{G}$ is leaf area or shoot length, respectively, and $t$ is time of leaf or shoot emergence $(t=0)$; leaf or shoot emergence $(t=$ 0 ) was extrapolated back by using the logistic equation.

Chlorophyll concentration. Total leaf chlorophyll was estimated with a portable chlorophyll meter (SPAD-502; Minolta Camera Co., Osaka, Japan), during the course of experiment. Data were converted into total concentration of chlorophyll $(\mathrm{Chl})$ per unit leaf area using a calibration equation: $C h l=0.0102 x$ $-0.0793, n=34, r^{2}=0.83$, where $x$ is the SPAD meter value. This regression $(P<0.0001)$ was established from preliminary destructive leaf sampling and chlorophyll extraction in $\mathrm{N}, \mathrm{N}$-dimethylformamide followed by spectrophotometer determinations (Lambda 6 UV-VIS; Perkin-Elmer, Bucks, U.K.) according to Moran (1982). Chlorophyll content (on leaf area and dry mass basis) was monitored during shoot development on control plants (6th node) and on plants used for carbon balance analysis (6th, 12 th, and 16th node).

Photosynthesis AND Respiration. Photosynthesis and respiration measurements were made on attached leaves at the 6th, 12th, and 16th node, with a portable gas exchange system (LI-6400; LICOR), from Mar. to June 2002. Measurements were done during clear days under naturally occurring photosynthetic photon flux density $(P P F D)$ and air temperature, and lasted 7-10 d for each node. Average temperatures during measurements were 20-24 ${ }^{\circ} \mathrm{C}$ and relative humidity inside the cuvette was $\approx 50 \%$ to $70 \%$. Photosynthetic rate $(A)$ and dark respiration $(R$, at the end of the dark period) were measured on 20 plants of each 6 th, 12 th, and 16 th node from the base.

In the greenhouse, in the early morning, we first measured the rate of dark respiration (mitochondrial) after darkening the cuvette with aluminum cover, because the rate of dark respiration could increase with accumulation of photosynthetates (Noguchi 
et al., 1996). Dark respiration was extrapolated using a $Q_{10}$ relation as follows:

$R=R_{\mathrm{n}} Q_{10}^{(T-T \mathrm{n}) / 10} \quad\left(Q_{10}=2.2\right)$

where $T_{\mathrm{n}}$ is the leaf temperature at which $R_{\mathrm{n}}$ was measured (dawn) and $T$ the leaf temperature at which $R$ was calculated (nighttime). For Mediterranean climates, $Q_{10}$ is expected to be around 2.2 (Larcher, 1983). Potential light-induced limitations in mitochondrial respiration were considered of minor quantitative importance in the calculation. Plants were then brought in the open for daily courses of gas exchange between the leaf and the atmosphere. Partial shade conditions allowed a better control of cuvette temperature while maintaining a similar light environment as in the greenhouse. Plants were measured in duplicate (each leaf sampled twice and measurements averaged) from dawn to dusk every 2-3 h.

DrY MASS AND CARBon CONTENT. After gas exchange measurements plants were harvested and the aboveground part separated into shoot and leaves. Leaves were oven dried at $65^{\circ} \mathrm{C}$ until constant weight, and then they were weighed for subsequent analysis.

Ash content was determined after combustion of the sample (individual leaves) in a muffle furnace for $5-6 \mathrm{~h}$ at $550{ }^{\circ} \mathrm{C}$. The gravimetric difference between the dry weight and the corresponding ash content was considered equivalent to total leaf carbohydrate content $\left(\mathrm{CH}_{2} \mathrm{O}\right)$; the organic nitrogen content volatilized during combustion was considered negligible to our purposes. Nitrogen content ranged from $5 \%$ to $6 \%$, without differences among stages of leaf development (Marchi, 2004).

Estimation OF SINK-SOURCE TRANSITION. The sink-source transition of the leaf was determined following the approach of Turgeon and Webb (1975) and Miyazawa et al. (2003). To estimate the leaf expansion when sink-source transition of $\mathrm{CH}_{2} \mathrm{O}$ occurs, the daily exchange rate of $\mathrm{CO}_{2}$ for each measured leaf and increment in weight of $\mathrm{CH}_{2} \mathrm{O}$ needed for growth of leaf surface over time were calculated. The age of expanding leaves used for measurements was estimated from their length and width (area) using the logistic equation described above.

The daily $\mathrm{CO}_{2}$ exchange rate was obtained by subtracting nighttime $\mathrm{CO}_{2}$ loss by respiration from daytime $\mathrm{CO}_{2}$ gain by photosynthesis. We integrated the diurnal photosynthetic carbon gain from dawn to dusk for each measured leaf. Photosynthetic rates at dawn and at dusk were considered equal to zero. To estimate nighttime $\mathrm{CO}_{2}$ loss by respiration, dark respiration rate was multiplied by the period in which $P P F D$ was zero; the dark respiration rate was assumed to be constant during the night since plants were grown in greenhouse conditions and estimated from the equation above. Air temperature at dawn was comparable to that experienced by plants during the night (averaged $11^{\circ} \mathrm{C}$ ), resulting in only minor differences in respiration rates. To convert daily assimilation rate from $\mu \mathrm{mol} \cdot \mathrm{m}^{-2} \cdot \mathrm{d}^{-1}$ to $\mathrm{g} \cdot \mathrm{d}^{-1}$ per leaf, values were multiplied by 30 (considering the atomic weight of $\mathrm{C}, \mathrm{H}$ and $\mathrm{O})$ and divided by 1 million and then scaled to leaf area.

The amount of $\mathrm{CH}_{2} \mathrm{O}$ needed for the expansion of leaf lamina was estimated through a linear model, being constant within the interval considered and increasing linearly with leaf age (and then with the percentage of leaf expansion). The slope of the regression that describes the relationship between $\mathrm{CH}_{2} \mathrm{O}$ content and leaf age represents the relative increment of $\mathrm{CH}_{2} \mathrm{O}$ per unit of time. The leaf age when the sink-source transition occurs corresponds to the intersection of the daily $\mathrm{CH}_{2} \mathrm{O}$ exchange rate with the line that represents the relative increment of $\mathrm{CH}_{2} \mathrm{O}$ per unit of time (slope of the regression).

STATISTICAL ANALYSIS. Plants were assembled in a completely randomized design. All data were averaged on a plant basis and individual means used for statistical analysis. One-way analysis of variance (ANOVA) for plant parameters was performed. Statistical analysis was conducted using Statistica statistical package (StatSoft; Tulsa, Okla.). Separation of means was performed using a least significant difference test at the 0.05 significance level. Fitting the logistic equations (with the least squares method) and linear regressions were performed with SigmaPlot software (Jandel Scientific). The completion of leaf area expansion was defined as the date when more than $99 \%$ of the maximum leaf area was reached on the logistic equation. The slope and $y$ intercept of regression lines were tested for homogeneity of error and coefficients were compared for significance, Student's $t$ test.

\section{Results}

Maximum shoot length (asymptote $a$ averaged for all logistic functions) was reached after $75 \mathrm{~d}$ from budbreak [early June; 74 $\pm 2.4 \mathrm{~cm}$ (mean $\pm \mathrm{SE})]$. The empirical growth model fitted the data well (Fig. 1 A and B). A higher absolute value of the coefficient $b$ (dimensionless units) indicates that the shoot reached

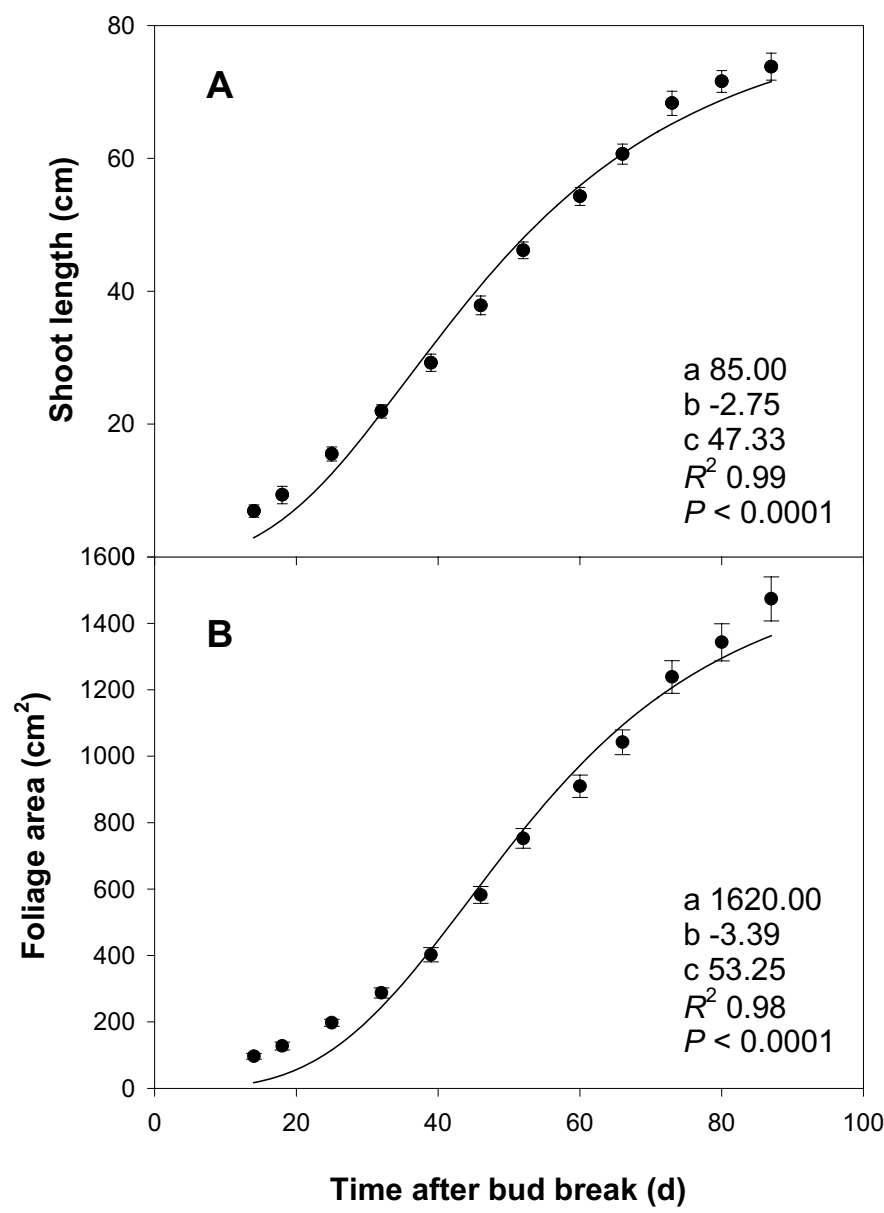

Fig. 1. Changes in shoot length (A) and foliage area (B) with time in control plants of Prunus persica. Data are the means $( \pm \mathrm{SE})$ of 10 plants. Logistic equations were fitted to the data with a non-linear least squares method. Regression parameters and significance of averaged functions are also reported in the frame. Averaged values of parameters of single functions for each plant are reported in the text. 
maximum length (or leaf area, see below) more rapidly, while a smaller value of the coefficient $c(d)$ indicates earlier completion of shoot growth (or leaf area). Averaged values for the coefficient $b$ and for the coefficient $c$ were $-3.34 \pm 0.16$ units and $42.24 \pm$ $0.75 \mathrm{~d}$, respectively (shoot length). Foliage area of the entire shoot attained maximum values of $1480 \pm 66.1 \mathrm{~cm}^{2}$ (March-June), following the logistic function. Averaged values for the coefficient $b$ and for the coefficient $c$ were $-3.82 \pm 0.1$ units and $50.04 \pm 0.51$ $\mathrm{d}$, respectively (foliage area).

Maximum relative growth rate was observed in late March for peach $(0.08$ and $0.07 / \mathrm{d}$ for shoot length and foliage area, respectively), and then values decreased rapidly during the season (Fig. $2 \mathrm{~A}$ and B).

The 6th, 12th, and 16th leaf reached full surface expansion $(90 \%)$ in $\approx 30 \mathrm{~d}$ from budbreak, ceasing growth when the terminal bud was set after 45-50 d (Fig. 3A-C) and averaged maximum leaf area was $53.27,43.8$, and $79.35 \mathrm{~cm}^{2}$, respectively. Values for coefficient $b$ never differed significantly between nodes (Table 1) (asymptote $a$ being fixed at 100\%). The coefficient $c$ was lower for the 12th leaf with respect to the 6th and 16th leaf.

Total chlorophyll concentration, on an area basis, increased linearly with leaf expansion across all nodes (Fig. 4A). Total chlorophyll content on dry mass basis again increased throughout leaf ontogenesis, though with marked differences between node 6 th and 16 th and node 12 th (Fig. 4B). In control plants (6th node, data not shown), total chlorophyll concentration increased in the first 50-60 d of leaf development, and then leveled off on averaged values of $0.43 \mathrm{~g} \cdot \mathrm{m}^{-2}$. Photosynthesis expressed on a chlorophyll content basis increased logarithmically with leaf age throughout all nodes (Fig. 4C).

Net daily $\mathrm{CO}_{2}$ assimilation (24 h) increased with leaf area expansion in all nodes. The net $\mathrm{CO}_{2}$ assimilation for $24-\mathrm{h}$ period increased significantly with leaf expansion (Fig. 5). The compensation expansion, the percentage of maximum leaf area at which nighttime respiration balances daytime photosynthesis so that net assimilation was zero, was considered equivalent to the point where the regression line met the $x$-axis passing through zero. The compensation expansion was achieved when the 6th (Fig. $5 \mathrm{~A})$ leaf reached $30 \%$ of full area expansion. The compensation expansion corresponded to $26 \%$ and $15 \%$ of full area expansion for the 12th (Fig. 5B) and 16th (Fig. 5C) leaf, respectively. Maximum daily assimilation derived from the regression was 307,398 and $380 \mathrm{mmol} \cdot \mathrm{m}^{-2} \cdot \mathrm{d}^{-1}$, respectively for the $6 \mathrm{th}, 12 \mathrm{th}$, and 16th leaf. Leaf surface corresponding to the compensation expansion was $15.3,12.4$ and $10.4 \mathrm{~cm}^{2}$, respectively for the 6 th, 12 th, and 16 th leaf.

A linear regression was forced through the origin between leaf age (estimated through the logistic equation) and total $\mathrm{CH}_{2} \mathrm{O}$ content (dry mass minus ash weight) for each layer (Fig. 6A-C). The sink-source transition for total $\mathrm{CH}_{2} \mathrm{O}$ in the leaf was defined as the point where the regression line of daily increase in total $\mathrm{CH}_{2} \mathrm{O}$ assimilation met the straight line of daily increase in total $\mathrm{CH}_{2} \mathrm{O}$ content. The straight line parallel to the $x$-axis indicated the slope value of the linear regression forced through the origin between total $\mathrm{CH}_{2} \mathrm{O}$ content and leaf age; regression coefficients and confidence intervals $( \pm 95 \%)$ for the 6 th, 12 th, and 16 th leaf node were derived from equations. The leaf was considered sink when total daily $\mathrm{CH}_{2} \mathrm{O}$ assimilation was less than the lower limit of confidence interval and source if more than the upper boundary. The sink-source transition was attained 11-12 d after budbreak (corresponding to $41 \%$ to $45 \%$ of full leaf expansion) for the 6 th (Fig. 7A) leaf, to after $\approx 7-9$ d (38\% to $52 \%$ of full expansion)

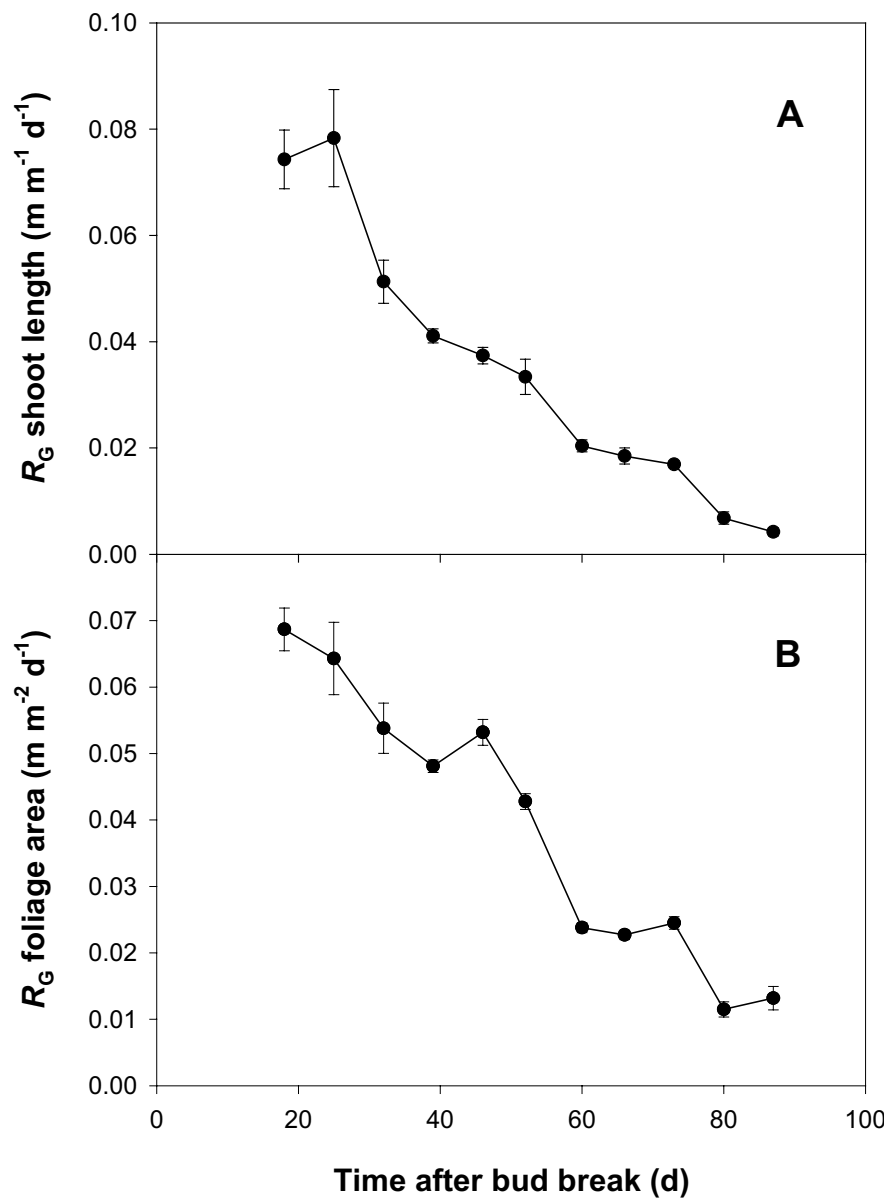

Fig. 2. Relative changes in shoot length $(\mathbf{A})$ and foliage area $(\mathbf{B})$ [relative growth rate, $\left(R_{\mathrm{G}}\right)$ ] during the growing season in control plants of Prunus persica. Data are the means $( \pm \mathrm{SE})$ of 10 plants.

for the 12th (Fig. 7B) leaf and after $9-10 \mathrm{~d}$ (32\% to $38 \%$ of full expansion) for the 16th (Fig. 7C) leaf.

\section{Discussion}

The increasing shoot length and leaf areas of peach followed the logistic growth model. In the model, a higher absolute value of coefficient $b$ indicates that growth had a slow latent period at first then a rapid phase attaining maximum values. A lower value of coefficient $c$ indicates earlier completion of shoot or leaf growth. Coefficient $b$ was higher in this deciduous than in the evergreen olive (Olea europaea L.) species as reported in a similar experiment (Marchi et al., 2005), though the two were grown under different environmental conditions. After an initial stage of slow growth peach attained maximum shoot length and foliage area (bud set) relatively early compared to olive. Analogously, in the present experiment coefficients $b$ and $c$ for foliage area development were fairly high. Differences between olive and peach were probably due to the growth habit of the evergreen versus the deciduous species. In the deciduous short-lived peach leaves, vegetative and reproductive organs compete for available resources in the early season before completion of photosynthesizing surface. Evergreen species have prompt growth resumption when temperatures are mild and soil moisture is still abundant. Miyazawa et al. (1998, 2003), Miyazawa and Terashima (2001) reported a sigmoid pattern for leaf expansion in evergreen broad- 

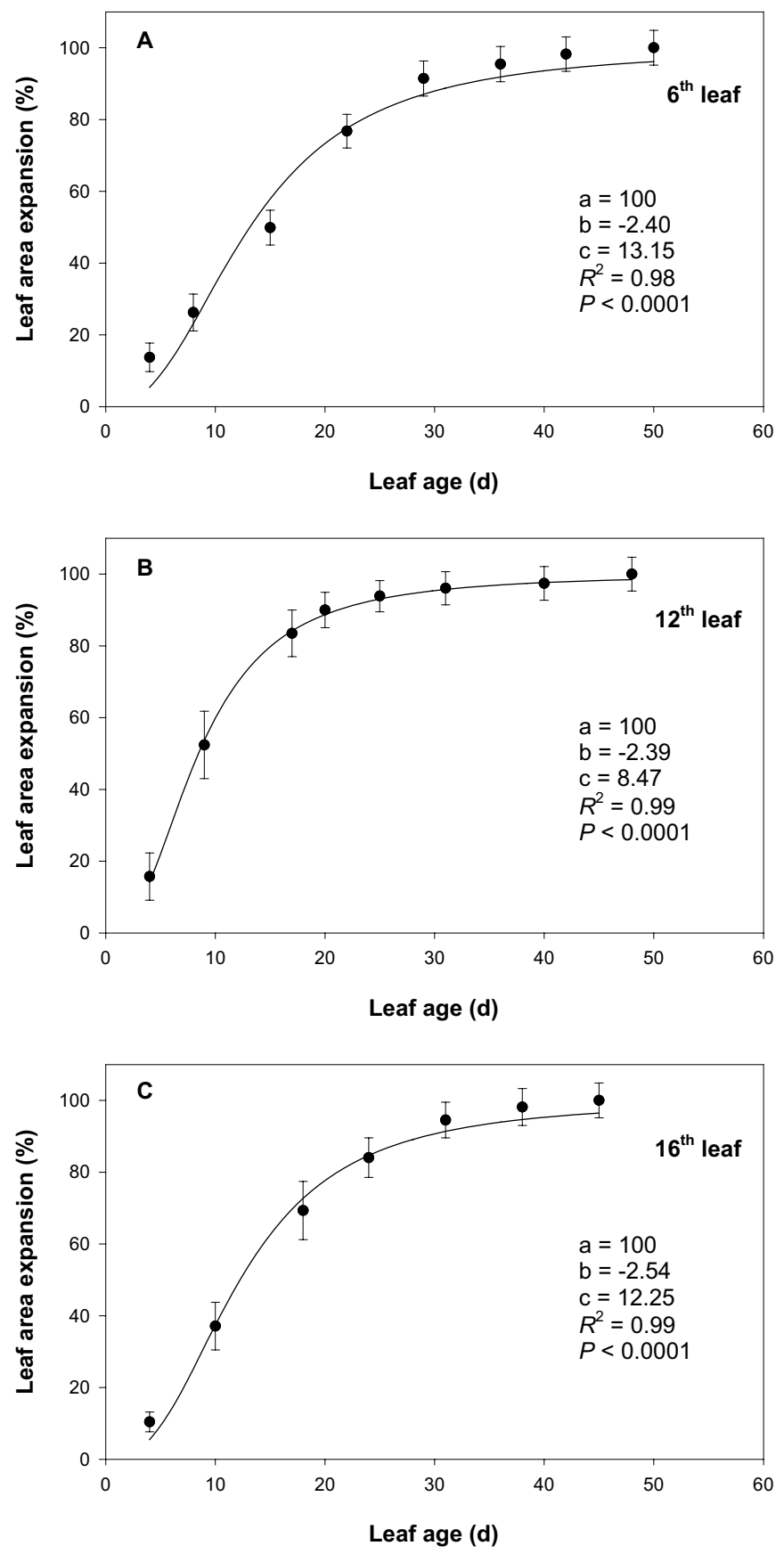

Fig. 3. Changes in percentage leaf area expansion with leaf age (6th, 12th, and 16th leaf; respectively, $\mathbf{A}, \mathbf{B}, \mathbf{C}$ ) in plants of Prunus persica. Data are the means $( \pm \mathrm{SE})$ of 10 plants. Logistic equations were fitted to the data with a nonlinear least squares method. Regression parameters and significance of averaged functions are also reported in the frame. Averaged values of parameters of single functions for each plant and significance are reported in Table 1.
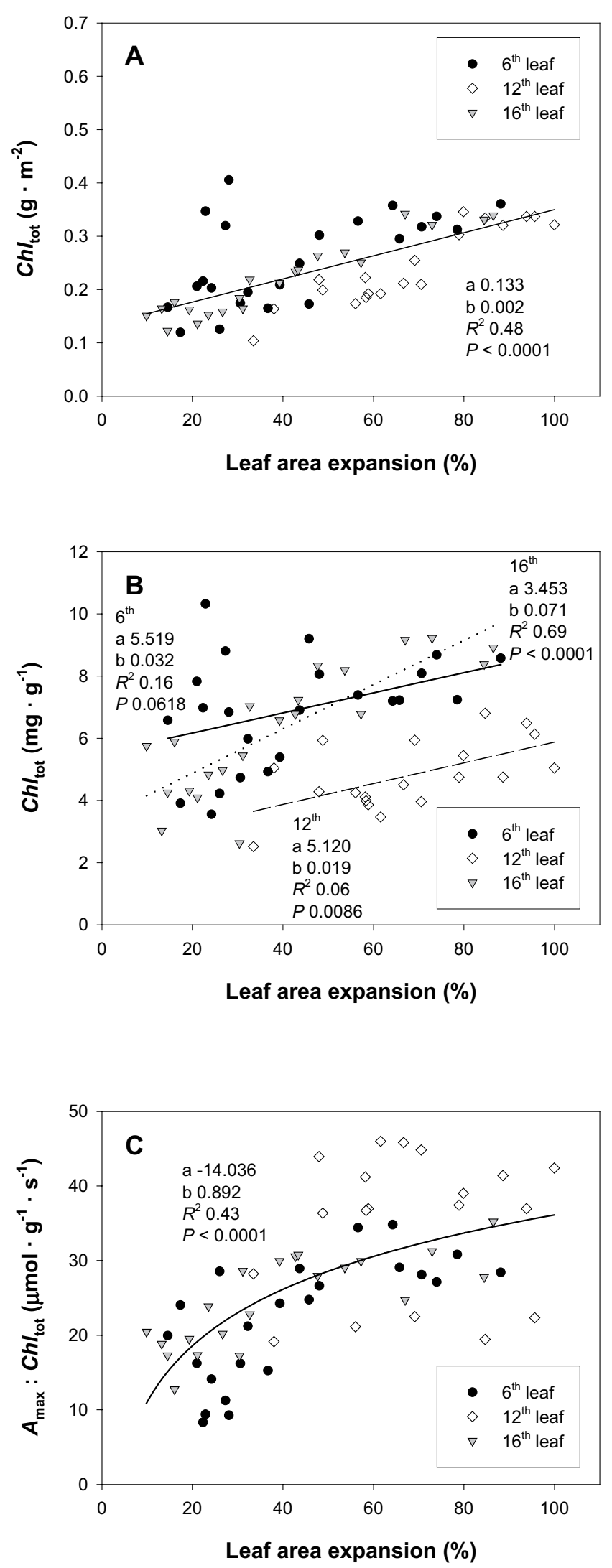

Fig. 4. Relationships between total chlorophyll content $\left(\mathrm{a}+\mathrm{b}, \mathrm{Ch} \mathrm{t}_{\mathrm{tot}}\right)$ on area (A) or dry mass $(\mathbf{B})$ basis, and maximum daily photosynthetic rate : total chlorophyll content ratio $\left(A_{\max }: C h l_{\text {tot }}\right)(\mathbf{C})$ and percentage of leaf area expansion in plants of Prunus persica (6th, 12th, and 16th node). Regression parameters of linear (A pooled, B individual) and logarithmic (C) relationships, and significance are also reported in the frame. 

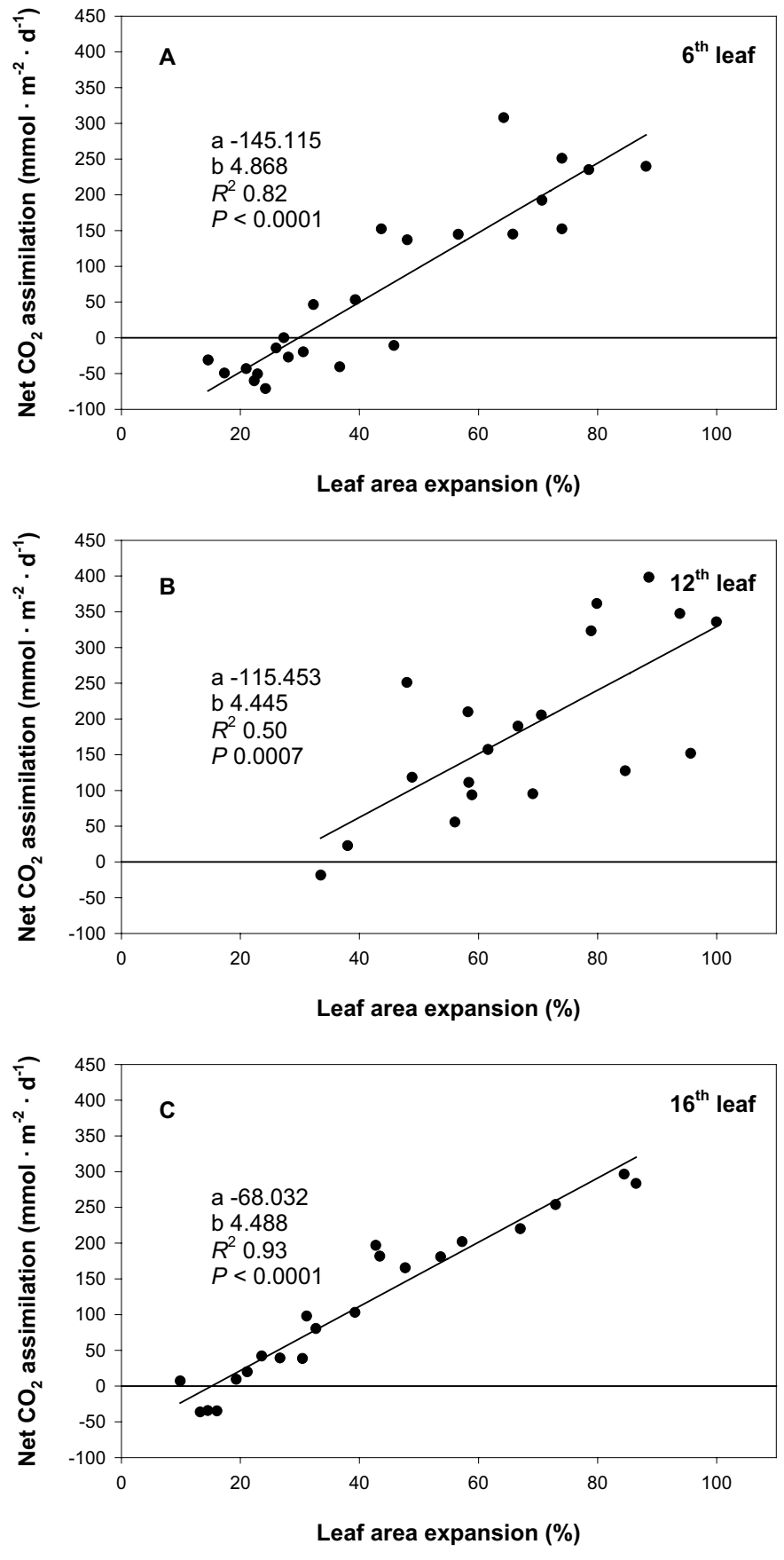

Table 1. Coefficients of the logistic function fitted to the data for percentage of area expansion of single leaves at the 6th, 12th, and 16th node of Prunus persica. Values are the mean \pm SE $(n=10)$. The asymptote $a$ is fixed at $100 \%$; $b$ is the width of the gradual transition from low to high values (dimensionless units); $c$ represents the value (d) in which the function is $50 \%$ of its width. The level of significance (ANOVA) is reported; different letters within the same column indicate significant differences between nodes at $P \leq 0.05$ (LSD test).

\begin{tabular}{lcr}
\hline Leaf & $b$ & \multicolumn{1}{c}{$c$} \\
\hline 6th & $-2.41(0.23)$ & $13.66(1.29) \mathrm{a}$ \\
12th & $-2.52(0.23)$ & $8.03(1.03) \mathrm{b}$ \\
16th & $-2.87(0.41)$ & $13.03(1.71) \mathrm{a}$ \\
ANOVA & & \\
$P$ & 0.5435 & 0.0102 \\
\hline
\end{tabular}

Fig. 5. (Left) Changes of daily net $\mathrm{CO}_{2}$ assimilation (subtracting nighttime $\mathrm{CO}_{2}$ loss by respiration from daytime $\mathrm{CO}_{2}$ gain by photosynthesis) with leaf area expansion (6th, 12th, and 16th leaf; respectively, A, B, C) in plants of Prunus persica. All data were fitted by a linear regression, whose intersection with $x$-axis passing through zero represents the compensation point of leaf area expansion. Regression parameters and significance are also reported in the frame.
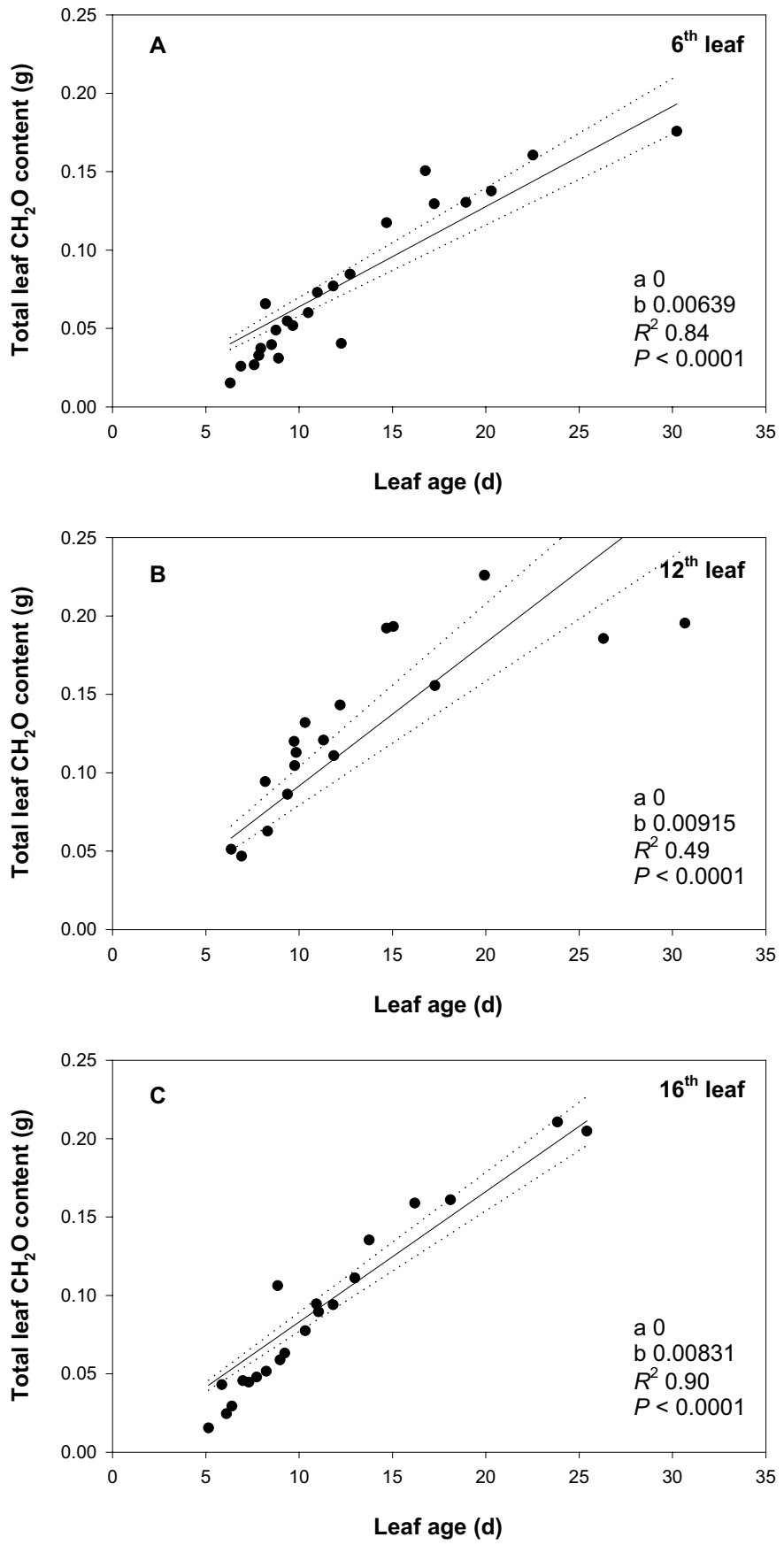

Fig. 6. Changes of total $\mathrm{CH}_{2} \mathrm{O}$ content (dry mass minus ash weight) and leaf age (from budbreak, estimated through the logistic equation) (6th, 12th, and 16th leaf; respectively, A, B, C) in plants of Prunus persica. All data were fitted by a linear regression forced through the origin. Regression parameters and significance are also reported in the frame. Confidence intervals $( \pm 95 \%)$ used for estimating the sink-source transition are depicted by dotted lines; 0.00586 and $0.00722,0.00788$, and $0.01042,0.00768$, and 0.00894 , respectively, for 6 th, 12th, and 16 th leaf node. 

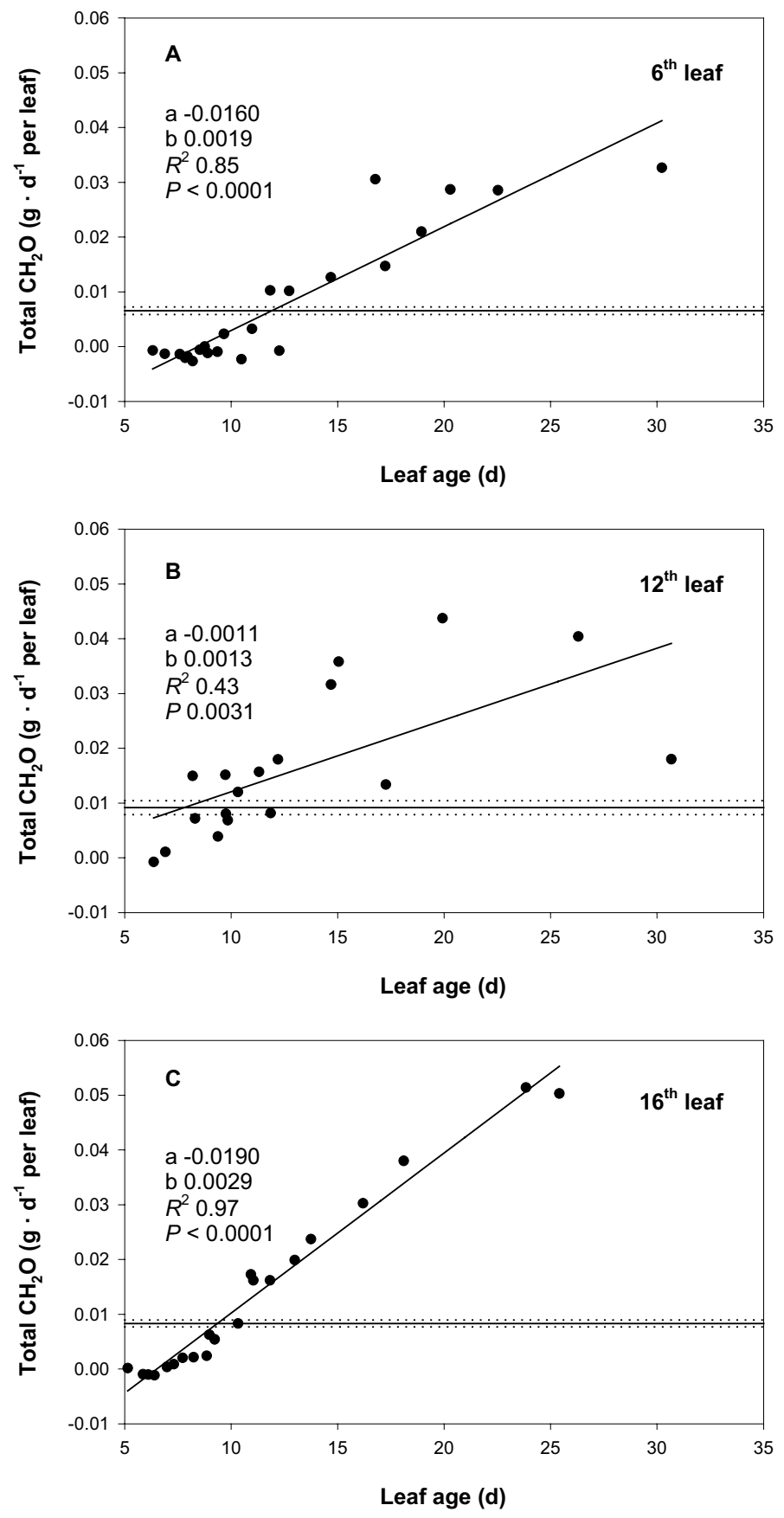

Fig. 7. Changes of daily total carbohydrate $\left(\mathrm{CH}_{2} \mathrm{O}\right)$ assimilation with leaf age (6th, 12th, and 16th leaf; respectively, A, B, C) in plants of Prunus persica. All data were fitted by a linear regression forced through the origin, whose intersection with the derivate (slope) of the daily increase in leaf carbohydrate content (symbolized by the line parallel to the $x$-axis; dotted lines stand for $\pm 95 \%$ confidence interval) represents the sink-source transition. Regression parameters and significance are also reported in the frame.

leaved trees and herbaceous species which both showed a steep growth rate without a marked latent phase. Hieke et al. (2002a, 2002b) used a sigmoid function for describing shoot and leaf development in the tropical evergreen lychee (Litchi chinensis Sonn.), which showed a latent phase at the early stage followed by an exponential growth phase.

The development of the 6th and 16th leaf showed similar dynamics, though with a time lag of $\approx 1$ month, and coefficients $b$ and $c$ were similar. The 12 th leaf showed a different growth pattern and lower photosynthetic pigment concentrations than the 6th and 16th leaf, perhaps from specific timing of nutrient supply or release from internal inhibition, tracking temperature patterns. Indeed, chloroplasts may have a supplementary role in internal regulation of $\mathrm{CO}_{2}$ assimilation taking the form of source-sink feedback control over photosynthesis.

Chlorophyll content increased with leaf expansion, though more clearly on an area than on dry mass basis, depending on the structure of leaves as leaf mass per area ratio increased with leaf expansion (data not shown). Nevertheless, photosynthesis expressed on a chlorophyll content basis increased with leaf age throughout all nodes. The increased net photosynthetic rate also can be attributed to the formation of additional chloroplasts and/or increased photochemical efficiency. Gas exchange and $\mathrm{CO}_{2}$ assimilation followed chlorophyll synthesis, as reported for other temperate deciduous species (Kennedy and Johnson, 1981). Net $\mathrm{CO}_{2}$ assimilation generally increases during leaf ontogeny reaching a maximum at about full leaf expansion and then decreasing during senescence in deciduous trees (Kennedy and Johnson, 1981). The photosynthetic maturity of chloroplast development was reached relatively late as compared to olive (Marchi et al., 2005). It has been illustrated that leaf-aging patterns may vary within a single species and even within an individual plant (Traw and Ackerly, 1995). Individual species, however, may differ considerably in patterns of nitrogen allocation and leaf mass per area among leaves on a shoot, thus affecting foliage photosynthesis.

Net daily $\mathrm{CO}_{2}$ assimilation was negative in the early stages of development, regardless of the node, because $\mathrm{CO}_{2}$ respired during the night in young leaves exceeded that assimilated during the day. In immature leaves respiration rates at night and in dark periods during the day may be almost identical, and a decrease in the respiratory capacity at night may first become evident during the import-export transition (Turgeon and Webb, 1975). Values of assimilation close to zero were estimated at a percent leaf expansion of about $30 \%$ (6th and 12th leaf) and 15\% (16th leaf), corresponding approximately to 9 (6th leaf) and 6 (12th and 16th leaf) d from budbreak. The daily balance of $\mathrm{CO}_{2}$ was positive at higher percentages of leaf area expansion than in olive trees (Marchi et al., 2005). Different transition patterns between peach and olive might be related to distinct drought avoidance strategies and leaf traits that are not competitive in the same environment.

The sink-source transition was poorly correlated to the leaf position along the shoot. The first leaf to export assimilates was the 12th in terms of leaf age, after 7-9 d from budbreak, at 38\% to $52 \%$ of full expansion. In terms of expansion, the first exporter leaf was the 16th, between $32 \%$ and $38 \%$, after $\approx 9-10 \mathrm{~d}$ from budbreak. Similar results have been reported by Kappes and Flore (1989) for sour cherry (Prunus cerasus L.) grown in pots and trained to single shoot. In these plants, the 7 th leaf began to export assimilates at $27 \%$ and $47 \%$ of full expansion, respectively for the first and second year of experiment. Analogously, the 10th leaf began to export assimilates at $48 \%$ to $72 \%$ of full expansion, depending on the year. Annual differences were ascribed to the different final leaf area achieved in the first and second year of experiment (different temperature and light intensity). Regardless of the node, the leaf began to be a net exporter of assimilates before reaching the maximum photosynthetic activity, which increased with leaf development. In terms of effective leaf area, the sink-source transition was attained at about 24,22 , and $30 \mathrm{~cm}^{2}$, respectively for the 6 th, 12 th, and 16 th leaf. The source activity 
started when leaves were rapidly growing and was similar in all nodes. Nevertheless, this shift occurred when the relative growth rate of single leaves (data not shown) was in the descending phase. Turgeon and Webb (1973) observed a similar trend in leaves of pumpkin (Cucurbita pepo L.), in which at the transition point from import to export, the relative growth rate of the lamina has decreased considerably. Expanding leaves may take advantage in competing for carbohydrates by having the import-export transition only after the relative growth rate has started decreasing. This is because rapidly developing tissues require a constant supply of nutrients. The relative growth rate of shoot length and foliage area declined steadily after leaf budbreak, as found in most dicotyledonous species (e.g., Arney, 1953). In pumpkin, however, Turgeon and Webb (1975) observed an increase of the relative growth rate between leaf unfolding and the stage when the leaf-tip stops importing, indicating an improvement in growth conditions from enhanced supply of imported substrates.

Cell division (structure) and chloroplast development (function) processes require large amounts of nitrogen and compete for nutrients throughout leaf development (Miyazawa et al., 2003). If, for the duration of sink-source transition, reliance were placed entirely on photosynthetically assimilated carbon, growth would be very affected under environmental constraints. During these periods, adequate substrates are assured through continuous import from mature parts of the plant (Turgeon and Webb, 1975). Below $30 \%$ to $50 \%$ of full expansion peach leaves would not respond to requirements from sinks demanding assimilates, being sinks themselves. Comparisons between co-occurring evergreen and deciduous species in Mediterranean-type agro-ecosystems are rare. In a companion study on olive cuttings developed in a growth chamber, the sink-source transition occurred before full leaf expansion, between $10 \%$ and $30 \%$ expansion depending on the node (Marchi et al., 2005). Further studies are warranted to clarify whether differences in sink-source transition between peach and olive may be modeled implementing plant and climatic data, and weighing the relative importance of leaf structural and functional characters.

\section{Literature Cited}

Arney, S.E. 1953. The initiation, growth, and emergence of leaf primordial in Fragaria. Ann. Bot. 17:477-492.

DeJong, T.M. 1999. Developmental and environmental control of drymatter partitioning in peach. HortScience 34:1037-1040.

Dickson, R.E. 1989. Carbon and nitrogen allocation in trees. Ann. Sci. For. 46:631-647.

Dickson, R.E. and J.G. Isebrand. 1991. Leaves as regulators of stress responses, p. 3-34. In: H.A. Mooney, W.E. Winner, and E.J. Pell (eds.). Response of plants to multiple stresses. Academic Press, San Diego. Escobar-Gutiérrez, A.J. and J.P. Gaudillére. 1996. Distribution, métabolisme et rôle du sorbitol chez les plantes supérieurs. Synthèse Agronomie 16:281-298.

Grossman, Y.I. and T.M. DeJong. 1994. PEACH: A simulation model of reproductive and vegetative growth in peach trees. Tree Physiol. 14:329-345.
Hieke, S., C.M. Menzel, and P. Lüdders. 2002a. Shoot development, chlorophyll, gas exchange and carbohydrates in lychee seedlings (Litchi chinensis). Tree Physiol. 22:947-953.

Hieke, S., C.M. Menzel, and P. Lüdders. 2002b. Effects of leaf, shoot and fruit development on photosynthesis of lychee trees (Litchi chinensis). Tree Physiol. 22:955-961.

Kappes, E.M. and J.A. Flore. 1989. Phyllotaxy and stage of leaf and fruit development influence initiation and direction of carbohydrate export from sour cherry leaves. J. Amer. Soc. Hort. Sci. 114:642-648.

Kennedy, R.A. and D. Johnson. 1981. Changes in photosynthetic characteristics during leaf development in apple. Photosynth. Res. 2:213-233.

Kozlowski, T.T. 1992. Carbohydrate sources and sinks in woody plants. Bot. Rev. 58:107-222.

Kriedemann, P.E. 1968. ${ }^{14} \mathrm{C}$ translocation patterns in peach and apricot shoots. Austral. J. Agr. Res. 19:775-780.

Larcher, W. 1983. Physiological plant ecology. Springer-Verlag, Berlin.

Marchi, S. 2004. Cambiamenti nelle caratteristiche strutturali e funzionali della foglia e relazioni source-sink durante lo sviluppo del germoglio in una specie arborea decidua (Prunus persica) ed in una sempreverde (Olea europaea). PhD Diss., Univ. of Pisa, Italy.

Marchi, S., L. Sebastiani, R. Gucci, and R. Tognetti. 2005. Changes in sink-source relationships during shoot development in olive. J. Amer. Soc. Hort. Sci. 130:631-637.

Miyazawa, S.I., S. Satomi, and I. Terashima. 1998. Slow leaf development of evergreen broad-leaved tree species in Japanese warm temperate forests. Ann. Bot. 82:859-869.

Miyazawa, S.I. and I. Terashima. 2001. Slow development of leaf photosynthesis in an evergreen broad-leaved tree, Castanopsis sieboldii: Relationships between leaf anatomical characteristics and photosynthetic rate. Plant Cell Environ. 24:279-291.

Miyazawa, S.I., A. Makino, and I. Terashima. 2003. Changes in mesophyll anatomy and sink-source relationships during leaf development in Quercus glauca, an evergreen tree showing delayed leaf greening. Plant Cell Environ. 26:745-755.

Moran, R. 1982. Formulae for determination of chlorophyllous pigments extracted with $\mathrm{N}, \mathrm{N}$-dimethylformamide. Plant Physiol. 69:1376-1381.

Noguchi, K., K. Sonoike, and I. Terashima. 1996. Acclimation of respiratory properties of leaves of Spinacia oleracea L., a sun species, and of Alocasia macrorrhiza (L.) G. Don., a shade species, to changes in growth irradiance. Plant Cell Physiol. 37:377-384.

Reich, P.B., M.B. Walters, and D.S. Ellsworth. 1992. Leaf life-span in relation to leaf, plant, and stand characteristics among diverse ecosystems. Ecol. Monogr. 62:365-392.

Traw, M.B. and D.D. Ackerly. 1995. Leaf position, light levels, and nitrogen allocation in five species of rain forest pioneer trees. Amer. J. Bot. 82:1137-1143.

Turgeon, R. and J.A. Webb. 1973. Leaf development and phloem transport in Cucurbita pepo: Transition from import to export. Planta 113:179-191.

Turgeon, R. and J.A. Webb. 1975. Leaf development and phloem transport in Cucurbita pepo: Carbon economy. Planta 123:53-62.

Turgeon, R. 1989. The sink-source transition in leaves. Annu. Rev. Plant Physiol. Plant Mol. Biol. 40:119-138.

Yin, X., J. Goudrian, E.A. Lantinga, J. Vos, and H.J. Spiertz. 2003. A flexible sigmoid function of determinate growth. Ann. Bot. 91:361-371. 